\title{
Pengembangan Program Pecahan Linier Dengan Transformasi Aljabar
}

\author{
Bobby Reynaldo ${ }^{1}$, Ratna Widyati ${ }^{2}$, Med Irzal $^{3}$ \\ Program Studi Matematika, Fakultas Matematika dan Ilmu Pengetahuan Alam \\ Universitas Negeri Jakarta \\ Jl. Rawamangun Muka, Rawamangun, Jakarta Timur 13220, \\ bobbyreynaldo@gmail.com
}

\begin{abstract}
Abstrak
Penyelesaian program pecahan linier pada penelitian ini menggunakan transformasi secara aljabar menjadi bentuk program linier yang lebih mudah didefi- nisikan. Setelah menjadi bentuk program linier kemudian diselesaikan menggu- nakan metode simpleks direvisi yang memiliki kelebihan dalam mengindentifi- kasi kasus khusus. Hasil optimal yang telah didapat ditransformasikan kembali dalam bentuk program pecahan linier. Juga dibuat sebuah aplikasi penyele- saiannya menggunakan metode tersebut untuk membantu perhitungan dengan cepat. Dari hasil pengujian untuk menyelesaikan permasalahan program pecahan linier dengan 10 variabel, 10 fungsi kendala, dan 10 kali iterasi, aplikasi mampu menyelesaikan seluruh proses hanya sekitar 0.026 detik.
\end{abstract}

Kata kunci : Optimasi, program pecahan linier, rasio, transformasi, program linier, metode simpleks direvisi.

\section{PENDAHULUAN}

Program pecahan linier adalah jenis khusus dari masalah program nonlinier di mana fungsi tujuan berbentuk rasio. Rasio yang terdapat pada program pecahan linier dibentuk dari dua fungsi tujuan linier dan kendala yang masih berupa fungsi linier. Isbell dan Marlow (1956) yang pertama kali mengidentifikasi contoh masa- lah program pecahan linier dan dipecahkan dengan urutan masalah program linier (Pandian \& Jayalakshmi, 2013).

Letak kelebihan program pecahan linier adalah pada fungsi tujuan yang berupa rasio. Rasio adalah perbandingan antara dua besaran atau lebih dimana perban- dingan harus menggunakan satuan yang sama. Rasio juga dapat diartikan sebagai suatu angka yang dapat menilai kinerja, menilai keefektifan ataupun menunjukkan hubungan antar suatu unsur dengan unsur lainnya. Optimasi dalam bentuk rasio se- ring ditemukan dalam permasalahan ekonomi, seperti analisis rasio likuiditas, rasio profitabilitas, rasio kepemilikan dan lainnya.

Sekarang ini sudah banyak metode yang dapat menyelesaikan permasalahan program pecahan linier diantaranya metode convex, metode transformasi Chaner dan Cooper, pecahan linier dengan fuzzy dan sebagainya. Penulisan ini membahas pendekatan transformasi baru sehingga program pecahan linier dapat ditransformasikan dan diselesaikan kedalam bentuk program linier. Metode ini dipilih karena secara manual program linier mudah. 


\section{KAJIAN TEORI}

\subsection{Matriks}

Didefinisikan matriks terlebih dahulu karena seluruh pembahasan program pecahan linier dan program linier akan dibentuk dalam matriks.

Beberapa pendefinisian tentang matriks (Eiselt \& Sandblom, 2007:1) yang akan digunakan adalah sebagai berikut.

Definisi 2.1.1. Matriks $\mathbf{A}$ adalah susunan dua dimensi dari elemen $a_{i j}$ yang berukuran $\mathrm{m}$ baris dan $n$ kolom (berordo $m \times n$ ) sehingga $a_{i j}$ yang merupakan elemen dalam baris $i$ dan kolom $j$. Jika $m=n$, dikatakan matriks persegi" jika $m=1$ dikatakan vektor baris, jika $n=1$ dikatakan vektor kolom, dan jika $m=n=1$ dikatakan skalar.

Definisi 2.1.2. Suatu matriks $\boldsymbol{A}=\left(a_{\boldsymbol{i}} \boldsymbol{j}\right)$ berordo $n \times n$, dapat dikatakan dengan matriks identitas apabila setiap elemen dengan elemen pada diagonal utamanya bernilai $a_{i j}=1$ jika $i=j$ dan $a_{i j}=0$ jika $i=j$. Matriks identitas dinotasikan dengan $\boldsymbol{I}$

Definisi 2.1.3. Transpose suatu matriks $\boldsymbol{A}=\left(a_{i j}\right)$ berordo $m \times n$ adalah matriks $A^{T}=\left(a_{i j}^{T}\right)$ berordo $n \times m$ sedemikian sehingga $\left(a_{i j}\right)=\left(a_{j i}^{T}\right)$. Jika $\boldsymbol{A}=\boldsymbol{A}^{T}$ dinamakan matriks simetris.

Definisi 2.1.4. Jika $\boldsymbol{A}$ dan $\boldsymbol{B}$ matriks berordo $n \times n$ sedemikian sehingga $\boldsymbol{A} \boldsymbol{B}=\boldsymbol{B} \boldsymbol{A}=\boldsymbol{I}$, dimana $\boldsymbol{I}$ matriks identitas maka matriks $\boldsymbol{B}$ disebut invers dari matriks $\boldsymbol{A}$ dan matriks $\boldsymbol{A}$ invers dari matriks $\boldsymbol{B}$. Notasi invers matriks $\boldsymbol{A}$ adalah $\boldsymbol{A}^{-1}$

\subsection{Program Linier}

Program linier yang ditemukan oleh L.W Kantorovich pada tahun 1939 dengan metode yang masih terbatas. Pada permasalahan program linier dikenal dua macam fungsi, yaitu fungsi tujuan (objective function) dan fungsi batasan (constraint function). Fungsi tujuan yaitu fungsi yang dapat menggambarkan hasil yang dicapai dengan tujuan yang optimal. Fungsi batasan atau lebih dikenal dengan fungsi kendala adalah fungsi yang menjadi kondisi, syarat, atau batasan yang harus terpenuhi. Fungsi tujuan program linier dapat dirumuskan sebagai berikut

$$
\text { Maksimum } Z=\boldsymbol{c}^{T} \boldsymbol{x}
$$

dengan kendala

$$
A x \leq b, \quad x \geq 0
$$

Dalam penyelesaian permasalahan program linear, tanda sisi kanan kendala harus bernilai non negatif, jika tanda pada bagian sisi kanan kendala bernilai negatif maka persamaan tersebut harus dikalikan dengan bilangan -1 agar tanda pada bagian sisi kanan kendala bernilai positif. 


\subsubsection{Metode Simpleks Direvisi}

Penggunaan metode simpleks ternyata bukan merupakan prosedur perhitung-an yang paling efektif dalam komputer. Alasannya karena metode simpleks masih mengerjakan beberapa variabel yang tidak diperlukan. Hal tersebut yang menda- sari perbaikan metode simpleks menjadi metode simpleks direvisi. Terdapat tiga tahapan dalam metode simpleks direvisi yaitu:
A. Perumusan Fungsi
B. Inisialisasi Matriks
C. Perhitungan (Penyelesaian)

\subsubsection{Khasus Khusu}

Kasus khusus yang dapat diidentivikasi oleh metode simpleks direvisi pada program linier adalah sebagai berikut:

- Optimasi alternative.

- Degenarasi.

- Solusit tak terbatas (Unbounded).

- Taka da daerah layak (Infeasible).

\subsection{Program Pecahan Linier (PPL)}

Program Pecahan Linier (PPL) secara luas dikembangkan oleh seorang matematikawan Hungaria B.Martos dan asosiasinya sekitar tahun 1960. Kelebihan metode ini ada pada fungsi tujuan yang merupakan sebuah pecahan (rasio). Fungsi tujuan program pecahan linier dapat dirumuskan sebagai berikut

dengan kendala

$$
\text { Maksimum } Z=\frac{\boldsymbol{c}^{T} \boldsymbol{x}+\beta}{\boldsymbol{d}^{T} \boldsymbol{x}+\alpha}
$$

$$
A x \leq b, \quad x \geq \mathbf{0}
$$

dengan $\boldsymbol{x} \in \mathbb{R}^{n}, \boldsymbol{x}$ adalah variabel keputusan, $\boldsymbol{c}, \boldsymbol{d} \in \mathbb{R}^{n}$ dan $\boldsymbol{b} \in \mathbb{R}^{m}$ adalah koefisienkoefisien yang diketahui, $\boldsymbol{A} \in \mathbb{R}^{m \times n}$ adalah matriks yang diketahui dan $\alpha, \beta \in \mathbb{R}$ adalah konstanta. Kendala permasalahan dibatasi wilayah layak $\left\{\boldsymbol{x} \mid \boldsymbol{d}^{T} \boldsymbol{x}+\beta \neq 0\right\}$. (Charnes \& Cooper, 1962)

\section{REKA YASA MODEL}

\subsection{Transformasi Program Pecahan Linier}

Asumsikan selalu terdapat daerah layak bukan himpunan, $S=\left\{\boldsymbol{x} \mid \boldsymbol{d}^{T} \boldsymbol{x}+\beta \neq\right.$ $0\}$ dan terbatas untuk $\boldsymbol{c}, \boldsymbol{d} \in \mathbb{R}^{n}$, dan $\boldsymbol{b} \in \mathbb{R}^{m}, \boldsymbol{A} \in \mathbb{R}^{m \times n}$ dan $\alpha, \beta \in \mathbb{R}$ yang memenuhi $\beta>0, \boldsymbol{d}=\left(d_{j 1}\right)$ dengan $d_{j 1} \geq 0$, dan $\boldsymbol{A}=\left(a_{i j}\right)$ dengan $a_{i j} \geq 0$, untuk $i=1,2,3, \cdots, m$ $j=1,2,3, \cdots, n$ untuk permasalahan program pecahan linier 


$$
\text { Maksimum } Z=\frac{\boldsymbol{c}^{T} \boldsymbol{x}+\beta}{\boldsymbol{d}^{T} \boldsymbol{x}+\alpha}
$$

dengan kendala

$$
A x \leq b, \quad x \geq 0
$$

akan ditransformasikan menjadi bentuk program linier dengan aljabar, menggunakan konstanta program pecahan linier yaitu $\alpha$ pada pembilang dan $\beta$ pada penyebut dibentuk sebagai berikut

$$
Z=\frac{\boldsymbol{c}^{T} \boldsymbol{x}+\beta}{\boldsymbol{d}^{T} \boldsymbol{x}+\alpha}=\frac{\boldsymbol{c}^{T} \boldsymbol{x}+\beta}{\boldsymbol{d}^{T} \boldsymbol{x}+\alpha}-\frac{\alpha}{\beta}+\frac{\alpha}{\beta}=\frac{\left(\boldsymbol{c}^{T} \beta-\boldsymbol{d}^{T} \alpha\right) \boldsymbol{x}}{\beta\left(\boldsymbol{d}^{T} \boldsymbol{x}+\alpha\right)}+\frac{\alpha}{\beta}
$$

didefinisikan

$$
\boldsymbol{g}^{T}=\frac{\boldsymbol{c}^{T} \beta-\boldsymbol{d}^{T} \alpha}{\beta} ; \quad \boldsymbol{y}=\frac{\boldsymbol{x}}{\boldsymbol{d}^{T} \boldsymbol{x}+\alpha} ; \quad h=\frac{\alpha}{\beta}
$$

didapatkan fungsi tujuan setelah transformasi yaitu

$$
Z=\boldsymbol{g}^{T} \boldsymbol{x}+h
$$

Kemuadn dicari fungsi kenda;anya. Invers fungsi dari $\boldsymbol{y}$ didapatkan sebagai berikut

$$
\boldsymbol{x}=\frac{\boldsymbol{y} \beta}{1-\boldsymbol{d}^{T} \boldsymbol{y}}
$$

kemudian dimasukan pada kendala maka kendala setelah transformasi menjadi

$$
\left(\boldsymbol{A} \beta+\boldsymbol{b} \boldsymbol{d}^{T}\right) \boldsymbol{y} \leq \boldsymbol{b}
$$

didefinisikan

$$
\boldsymbol{K}=\boldsymbol{A} \beta+\boldsymbol{b d}^{T}
$$

maka di dapatkan kendala setelah transfromasi yaitu

$$
K \boldsymbol{K} \leq \boldsymbol{b}, \quad \boldsymbol{y} \geq \mathbf{0}
$$

Catatan 3.1.1. Konstanta pada program linier akan dimasukkan setelah didapat hasil yang optimal, maka persamaan program linier yang akan diproses pada metode simpleks direvisi adalah

$$
Z=\boldsymbol{g}^{T} \boldsymbol{x}
$$

Kemudian optimasi yang didapa ditambah konstanta $h$ untuk mendapatkan hasil akhirnya 


\subsection{Langkah - Langkah Penyelesaian Manual}

Untuk menyelesaikan optimasi program pecahan linier dengan transformasi menggunakan aljabar konstanta menjadi bentuk program linier, terdapat tiga tahapan yang harus dikerjakan yaitu:

A. Transformasi program pecahan linier menjadi program linier.

B. Penyelesaian program linier dengan metode simpleks direvisi.

C. Trasnformasi kembali variabel keputusan $\boldsymbol{y}$ menjadi $\boldsymbol{x}$.

\subsection{Pembuatan Aplikasi Program Pecahan Linier}

Langkah dalam membuat aplikasi yaitu:

- Menentukan perangkat lunak yang digunakan

- Membangun Algoritma

- Membuat fungsi pemrograman

- Membuat infterface-nya

\section{APLIKASI HASIL MODEL}

\subsection{Contoh Kasus Program Pecahan Linier}

Seseorang ingin menginvestasikan asetnya dalam bidang !urniture. Bahan da- sar yang sering digunakan yaitu kayu jati, kayu sungkai, kayu akasia, dan kayu mahoni. Furniture yang dibuat dari bahan tersebut adalah 1 set lengkap (meja lemari kursi pintu jendela dll) untuk rumah bertipe besar. Diperlukan biaya awal untuk membeli peralatan-peralatan dan mesin sekitar 700 juta. Gudang sudah ter- sedia dan dapat menampung bahan mentah untuk dijadikan sekitar 20 set lengkap. Untuk memaksimalkan gudang yang sudah tersedia maka gudang harus terisi minimal untuk 16 set lengkap. Dengan menggambil contoh data beberapa perusahaan di bidang furniture, didapatkan rata-rata biaya yang habiskan untuk membuat furni- ture 1 set lengkap dengan berbagai bahan kayu terdapat dalam table berikut (dalam Juta)

Tabel 1: Rata-rata Daftar Harga Furniture

\begin{tabular}{|c|c|c|c|c|c|c|}
\hline Jenis Kayu & $\begin{array}{c}\text { Bahan } \\
\text { Mentah } \\
\text { (Log Kayu) }\end{array}$ & Pegawai & $\begin{array}{c}\text { Bahan } \\
\text { Kimia }\end{array}$ & $\begin{array}{c}\text { Peralatan } \\
\text { Sekali Pakai }\end{array}$ & $\begin{array}{c}\text { Biaya } \\
\text { Operasional } \\
\text { dan tahap } \\
\text { finisihing }\end{array}$ & $\begin{array}{c}\text { Rata-rata } \\
\text { Harga Jual } \\
1 \text { Set } \\
\text { Lengkap }\end{array}$ \\
\hline Jati & 148 & 30 & 8 & 11 & 6 & 347 \\
\hline Sungkai & 126 & 27 & 7 & 10 & 5 & 246 \\
\hline Akasia & 110 & 24 & 7.5 & 8.5 & 4 & 233 \\
\hline Mahoni & 96 & 21 & 7 & 9 & 4 & 228 \\
\hline
\end{tabular}

Maksimal investasi yang akan di berikan pada setiap bidang adalah sebagai berikut:

Investasi biaya maksimal untuk bahan mentah (log kayu) :2 Miliar

Investasi biaya maksimal untuk pegawai

: 420 Juta

Investasi biaya maksimal untuk bahan kimia

: 125 Juta 
Investasi biaya maksimal untuk peralatan sekali pakai

: 160 Juta

Investasi biaya maksimal untuk operasional dan finisihing

: 100 Juta

Dengan kebutuhan dana sebesar itu terlalu beresiko jika hanya memikirkan keuntungan yang maksimal. Untuk itu fungsi tujuan utama adalah memaksimalkan rasio pengembalian dana investasi, atau dengan kata lain memaksimalkan seluruh hasil penjualan dengan meminimalkan dana investasi yang digunakan.

\subsection{Hasil Penyelesaian Contoh Kasus Menggunakan Aplikasi}

Pada contoh kasus yang sudah diberikan terdapat data yang dapat di bangun menjadi suatu fungsi. Untuk membangun fungsi di didefinisikan variabelnya yaitu

$\mathrm{x}_{1}$ : satu set lengkap furniture dengan bahan dasar kayu jati.

$\mathrm{x}_{2}$ : satu set lengkap furniture dengan bahan dasar kayu sungkai.

$\mathrm{x}_{3}$ : satu set lengkap furniture dengan bahan dasar kayu akasia.

$\mathrm{x}_{4}$ : satu set lengkap furniture dengan bahan dasar kayu mahoni.

Tahap selanjutnya adalah mengidentifikasikan fungsi tujuannya. Karena tujuan utamanya memaksimalkan seluruh hasil penjualan dengan meminimalkan dana investasi yang digunakan maka akan dibuat fungsi tujuan dengan membandingkan harga jual dengan modal yang dibutuhkan. Fungsi tujuan dapat dibentuk sebagai berikut

$$
\text { Memaksimalkan } Z=\frac{347 x_{1}+246 x_{2}+233 x_{3}+228 x_{4}}{203 x_{1}+175 x_{2}+154 x_{3}+137 x_{4}+700}
$$

Setalah menentukan fungsi tujuan, langkah selanjutnya adalah mengidentifikasi adalah fungsi kendalanya dari contoh data yang dimiliki sebagai berikut:

1. Karena keterbatasan investasi pada bahan mentah, maka didapatkan

$$
148 x_{l}+126 x_{2}+110 x_{3}+96 x_{4} \leq 2000
$$

2. Karena keterbatasan investasi untuk pegawai, maka didapatkan

$$
30 x_{l}+27 x_{2}+24 x_{3}+21 x_{4} \leq 420
$$

3. Karena keterbatasan investasi pada bahan kimia, maka didapatkan

$$
8 x_{1}+7 x_{2}+7.5 x_{3}+7 x_{4} \leq 125
$$

4. Karena keterbatasan investasi pada peralatan yang sekali pakai, maka didapatkan

$$
11 x_{1}+10 x_{2}+8.5 x_{3}+9 x_{4} \leq 160
$$

5. Karena keterbatasan investasi biaya operasional dan tahap finisihing, maka didapatkan

$$
6 x_{1}+5 x_{2}+4 x_{3}+4 x_{4} \leq 100
$$

6. Untuk memaksimalkan gudang maka didapatkan

$$
x_{1}+x_{2}+x_{3}+x_{4} \geq 16
$$


Funsi tujuan dan fungsi kendala kini telah lengkap. Selanjutnya penyelesaian contoh kasus di atas menggunakan aplikasi penghitungan program pecahan liner adalah sebagai berikut. Hasil transformasi fungsi tujuan program pecahan linier menjadi program linier yaitu

$$
Z=347 y_{1}+246 y_{2}+233 y_{3}+228 y_{4}+0
$$

Hasil transformasi fungsi kendala sebagai berikut

$$
\begin{aligned}
& 509600 y_{1}+438200 y_{2}+385000 y_{3}+341200 y_{4} \leq 2000 \\
& 106260 y_{1}+92400 y_{2}+81480 y_{3}+72240 y_{4} \leq 420 \\
& 30975 y_{1}+26775 y_{2}+24500 y_{3}+22025 y_{4} \leq 125 \\
& 40180 y_{1}+35000 y_{2}+30590 y_{3}+28220 y_{4} \leq 160 \\
& 24500 y_{1}+21000 y_{2}+18200 y_{3}+16500 y_{4} \leq 100 \\
& 3948 y_{1}+3500 y_{2}+3164 y_{3}+2892 y_{4} \geq 16
\end{aligned}
$$

Hasil dari variabel keputusan adalah

$$
\begin{array}{ll}
y_{1}=0.00233918 & ; x_{1}=8 \\
y_{2}=0 & ; x_{2}=0 \\
y_{3}=0 & ; x_{3}=0 \\
y_{4}=0.00233918 & ; x_{4}=8
\end{array}
$$

Dengan hasil optimal yaitu

$$
Z=1.34503
$$

artinya rasio terbesar dari hasil penjualan adalah sebesar 1.34503 kali dibandingkan dengan modal investasi yang digunakan.

\subsection{Analisis Dan Kinerja Aplikasi}

Tujuan utama pembuatan aplikasi adalah menyelesaikan permasalahan dengan cepat. Dari hasil pengujian untuk menyelesaikan permasalahan program pecahan linier dengan 10 variabel, 10 fungsi kendala, dan 10 kali iterasi, aplikasi mampu menyelesaikan seluruh proses hanya sekitar 0.026 detik.

\section{PENUTUP}

\subsection{Kesimpulan}

Berdasarkan hasil dan pembahasan di atas, maka dapat diambil kesimpulan sebagai berikut: 
1. Transformasi program pecahan linier menjadi bentuk program linier adalah sebagai berikut

dengan

$$
Z=\boldsymbol{g}^{T} \boldsymbol{x}+\boldsymbol{h}
$$

$$
\boldsymbol{g}^{T}=\frac{\boldsymbol{c}^{T} \beta-\boldsymbol{d}^{T} \alpha}{\beta} ; \quad \boldsymbol{y}=\frac{\boldsymbol{x}}{\boldsymbol{d}^{T} \boldsymbol{x}+\alpha} ; \quad h=\frac{\alpha}{\beta}
$$

dan fungsi kendala setelah trasnformasi menjadi

dengan

$$
K \boldsymbol{y} \leq \boldsymbol{b}, \quad \boldsymbol{y} \geq \mathbf{0}
$$

$$
\boldsymbol{K}=\boldsymbol{A} \beta+\boldsymbol{b d ^ { T }}
$$

2. Transformasi hasil optimal dari program linier yaitu y ditransformasi kembali menjadi bentuk program pecahan linier yaitu $\mathrm{x}$ adalah sebagai berikut

$$
\boldsymbol{x}=\frac{\boldsymbol{y} \beta}{1-\boldsymbol{d}^{T} \boldsymbol{y}}
$$

3. Dibuat perangkat lunak yaitu sebuah aplikasi penghitungan program pecahan linier menggunakan MATLAB R2012b untuk membantu penghitungan dengan cepat. Dari hasil pengujian untuk menyelesaikan permasalahan program pecahan linier dengan 10 variabel, 10 fungsi kendala, dan 10 kali iterasi, aplikasi mampu menyelesaikan seluruh proses hanya sekitar 0.026 detik.

\subsection{Saran} berikut:

Berikut beberapa saran untuk pengembangan selanjutnya adalah sebagai

- Aplikasi yang sudah dibuat masih memiliki banyak kelemahan, salah satunya tidak bisa membaca konstanta bila ditulis paling awal sebelum variabel, untuk itu aplikasi masih harus dilakukan pemuktahiran

- Penyelesaian program pecahan linier masih menggunakan asumsi, untuk penelitian selanjutnya dapat mengembangkan penyelesaian program pecahan linier dengan lebih luas dan tanpa menambahkan asumsi.

- Penyelesaian program linier menggunakan metode simpleks direvisi dapat di- kembangakan dengan metode lainnya seperti metode primal dual path follo- wing titik interior, convex set atau dengan metode lain tentu dengan menekankan kelebihan metode masing-masing. 


\section{DAFTAR PUSTAKA}

Bitran, G.R. and A.G. Novaes, 1973. "Linear Programming with a Fractional Objective Function". Operations Research, 21(1), 22-29. [ONLINE] Tersedia: http://pubsonline.informs.org/doi/abs/10.1287/opre.21.1.22 Diakses Sabtu, 12 Maret 2016 Pukul 16.07 WIB.

Chandra, S. Jayadeva. and Aparna M. 2009. Numerical Optimization Applications.

Alpha Science International.

Charnes, A. and W.W. Cooper, 1962. "Programming with linear fractional". Naval Research Logistics Quaterly, Vol. 9: 181-186. [ONLINE] Tersedia: http://onlinelibrary.wiley.com/doi/10.1002/nav.v9:3-4/issuetoc Diakses Minggu, 6 Desember 2015 Pukul 18.31 WIB.

Dantzig, G.B, Thapa, M.N. 1997. Linear Programming 1 : Introduction. New York

: Springer Berlin Heidelberg.

Dimyati, Tjutju T., Dimyati, Ahmad. 2003. Operation Research, Model-model Pengambilan Keputusan. Bandung: Sinar Baru Algesindo.

Eiselt, H.A., Sandblom, C.-L. 2007. Linear Programming and its Application. New

York : Springer Berlin Heidelberg.

Hillier and Lieberman. Terjemahan : Dewa, P.M, The Jin Ai, Wigati, Selamat Setio, Hardjono, D. 2008. Penelitian Operasional. Yogyakarta : ANDI.

Pandian, P. and M. Jayalakshmi, 2013. "On Solving Linear Fractional Programming Problems", Modern Applied Science, Vol. 7, No. 6; 2013. [ONLINE] Tersedia: http://dx.doi.org/10.5539/mas.v7n6p90 Diakses Minggu, 6 Desember 2015 Pukul 15.22 WIB.

Saha, S.K., dkk. 2015. "A New Approach of Solving Linear Fractional Programming Problem (LFP) by Using Computer Algorithm". Open Journal of Optimization, 4, 74-86. [ONLINE] Tersedia: http://dx.doi.org/10.4236/ojop.2015.43010 Diakses Senin, 7 Desember 2015 Pukul 20.42 WIB.

Zuhanda, M. Khahfi. 2013. "Optimasi Prgoram Linier Pecahan Dengan Fungsi Tujuan Berkoefisien Interval". Skripsi. FMIPA, Matematika, Universitas Sumatra Utara. 